\title{
AFETO, INTENSIDADE E CONFIANÇA NA EXPERIÊNCIA ANALÍTICA: ALGUMAS CONSIDERAÇÕES SOBRE A HETERODOXIA CLÍNICA DE S. FERENCZI
}

Vivian Heringer Pizzinga e Márcia Arán

Vivian Heringer Pizzinga

Psicóloga, especialista em Terapia de Família pelo Instituto de Psiquiatria (Ipub/ UFRJ); mestre em Saúde Coletiva no Instituto de Medicina Social (IMS/Uerj).

Márcia Arán Psicanalista, professora do Instituto de Medicina Social da Uerj; doutora em Saúde Coletiva (IMS/Uerj), membro do Espaço Brasileiro de Estudos Psicanalíticos.
RESUMO: Pretende-se examinar a atualidade das contribuições do pensamento de Sándor Ferenczi para a construção da experiência analítica. Em um primeiro momento, visa-se discutir os conceitos de afeto e intensidade em sua obra, para, em seguida, examinar com mais profundidade algumas questões por ele levantadas acerca do lugar do analista e da importância da confiança e da sinceridade do analista no dispositivo analítico, questões essas intensificadas quando de sua última inventiva metodológica, a saber, a análise mútua.

Palavras-chave: Clínica psicanalítica, transferência, tato, afeto.

ABSTRACT: Affection, intensity and confidence in the analytical experience: a few considerations about the S. Ferenczi clinical heterodoxy. This article aims at studying the currentness of the contributions of Sándor Ferenczi's thought in the building of the psychoanalytical experience. To begin with, the affection and intensity concepts as described in his work will be put into discussion and, subsequently, some issues he raised concerning the analyst's place as well as the analyst's confidence and frankness in the analytical apparatus will be examined in detail. Such issues have been intensified in Ferenczi's late methodology, known as mutual analysis.

Keywords: Psychoanalytical clinic, transference, tact, affection.

\section{APRESENTAÇÃO}

Sandór Ferenczi, psicanalista húngaro identificado com o tratamento de 'casos difíceis', trouxe reflexões importantes para o âmbito da clínica psicanalítica, uma vez que, como aponta Birman (1988, p. 22), a metodologia do processo analítico constituiu-se na "problemática axial de sua pesquisa em psicanálise", tendo sido Ferenczi um psicanalista de fato ao não perder de vista a incessante pergunta sobre o que era a psicanálise e o que é ocupar o lugar do analista. 
No intuito de resolver os problemas concernentes a tais questões e na tentativa de ultrapassar a perplexidade diante dos numerosos impasses que a clínica psicanalítica pode trazer, Ferenczi buscou de modo constante remodelar a forma como se situava no lugar de analista, não se eximindo de alterar a compreensão tanto técnica quanto teórica da experiência psicanalítica e dos casos com os quais se deparava.

Ferenczi passou a notar que a estagnação de certos processos terapêuticos não podia ser resolvida se o foco continuasse exclusivamente voltado para a associação livre e, como se pode ler em seus textos, sobretudo aqueles escritos a partir de 1928, procurava identificar o que, na situação analítica em si, e não na suposta resistência dos pacientes, podia estar atrelado diretamente aos resultados terapêuticos que não levavam à melhora esperada.

Assim, Ferenczi buscou construir um caminho heterodoxo, dando ênfase ao trânsito de afetos que constitui a experiência psicanalítica em detrimento da rememoração consciente por meio de um processo majoritariamente verbal. Como nos recorda Balint (1968/1993), Ferenczi acreditava que devia encontrar técnicas que pudessem ajudar o paciente, enquanto ele ainda comparecia ao tratamento. Nesses termos, visava não abandonar o paciente antes de poder proporcionar-lhe algum alívio duradouro do sofrimento que apresentava, mesmo que precisasse transgredir e tornar elástica a técnica analítica clássica com o intuito de fugir à improficuidade do dispositivo analítico.

Como aponta Borges (2002), Ferenczi, ao propor a elasticidade da técnica analítica, que será abordada adiante, intuía o trabalho de análise e cada momento dela como sendo inaugural. Neste sentido, a narrativa não pode dar conta apenas de certas experiências-limite e a clínica convoca o encontro com o múltiplo e o singular, em detrimento do conhecido e do dado. A autora assinala o limite de um modelo que se centra na representação e no recalque, ao afirmar, referindo-se a Ferenczi: "Recupera-se (...) a noção de inconsciente como campo de intensidades, fluxos, transformações constantes; não só como lugar do reprimido, mas, para além do representado, espaço das intensidades (...)” (BORGES, 2002, p. 202).

Esse "além do representado" a que a autora alude é tratado por Ferenczi, em Notas e fragmentos, texto póstumo, na passagem de 26 de outubro de 1932. Nela o autor refere-se à existência, nos adultos, de uma "lembrança imobilizada no corpo", tratando-se de lembranças subjetivas que dizem respeito a sensações corporais, e que, nestas condições, no âmbito da técnica, não justificam a exigência de uma "rememoração consciente de algo que nunca foi consciente" (FERENCZI, 1932, 1991, p. 268). Dessa maneira pode-se observar que Ferenczi, com o fito de abarcar o sofrimento que não se esgota pela palavra, e movido pela ideia de que o conforto não um é elemento da clínica psicanalítica (PINHEIRO, 1994), empreendeu mudanças técnicas constantes, conferindo lugar de destaque à relação 
entre analista e paciente e à confiança que é aí construída: o trânsito de afetos imbricado nessa relação talvez seja um dos aspectos do pensamento ferencziano mais significativos e de maior relevância para este trabalho e que já se faziam notar quando de suas contribuições à noção de transferência.

\section{TRANSFERÊNCIA COMO INTROJEÇÃO}

Na medida que se pode considerar que são as qualidades do encontro dos personagens da cena analítica o que confere mobilidade em direção à cura, isto é, como lembra Ferenczi subscrevendo Freud (1909/1991), são as transferências que cuidam do neurótico, independendo da especificidade do tratamento aplicado, pode-se depreender que se há elementos de dificuldade nesse encontro, conscientes ou não, a experiência pode trazer resultados negativos ou, no mínimo, inocuidade. A relação transferencial é fundamental para a construção da experiência psicanalítica e Ferenczi buscou enxergar a intensidade de tal processo e a afetividade aí presente, concebendo-a a partir de sua ligação com o conceito de introjeção.

Como indica Lagache (1980), a transferência, de acordo com a perspectiva ferencziana, constitui-se em uma classe de introjeções que, ao longo do tratamento analítico, acabam por tomar como objeto a figura do médico. No texto Transferência e introjeção (1909/1988), Ferenczi apresenta, de início, uma metáfora química para elucidar o que ocorre no tratamento psicanalítico, comparando a psicanálise a uma espécie de catálise. O analista funcionaria como um catalisador, cuja função seria atrair os afetos liberados pela transferência. De acordo com Ferenczi, haveria uma tendência geral dos neuróticos para a transferência, que buscariam "incluir em sua esfera de interesses uma parte tão grande quanto possível do mundo exterior, para torná-lo objeto de fantasmas conscientes ou inconscientes” (1909/1988, p. 36).

Segundo Verztman (2002), “a introjeção é o processo permanente segundo o qual os neuróticos se vinculam aos outros”, todavia, cabe salientar que o processo introjetivo visa a pulsão e não o objeto. Nestes termos, a pulsão deixa de funcionar como agente externo, integrando-se ao eu. Assim, o processo introjetivo seria responsável pela capacidade do infante de se inserir no mundo, ou seja, pela capacidade do eu de ampliar os laços de dependência com os outros (VERZTMAN, 2002). Haveria, ipso facto, uma dilatação do ego do neurótico, mecanismo constituinte da transferência, de acordo com Ferenczi.

Reis (2004) admite que, para o autor húngaro, a transferência seria um processo criador, e não unicamente uma atualização de memórias infantis recalcadas. No cerne do processo transferencial estaria a transposição de afetos, e não de representações, conteúdos ou fantasmas apenas. Reis aponta a introjeção proposta por Ferenczi como um alargamento do eu, em que se daria, ao mesmo tempo, a 
construção do eu e do mundo. Neste sentido, de acordo com a autora, a relação própria da situação analítica é criadora e permeada de intensidades afetivas. Destarte, o problema residiria em encarar a transferência exclusivamente como forma de resistência, o que esgota e limita a compreensão do que pode ocorrer na relação entre o paciente e seu analista. É isso também o que aponta Peixoto Jr. que, em seu artigo sobre M. Balint, traz a hipótese de uma "transferência produtiva em análise que não passaria pelo viés da resistência, e que remeteria necessariamente ao exame das condições de produção de sentido no processo de subjetivação” (PEIXOTO JÚNIOR, 2003, p. 224). Com isso, busca-se ultrapassar a compreensão da transferência com base apenas em uma concepção do aparato psíquico restrita ao modelo da representação e do recalcamento. Essa é a preocupação que está, de igual modo, na base da inquietação de Ferenczi, quando se interroga sobre aquilo que não é abarcado pelo processo verbal na análise, na tentativa de ampliar a concepção da experiência psicanalítica e evitando, por conseqüência, um excesso de intelectualização.

\section{A DIMENSÃO AFETIVA PRESENTE NO SENTIR COM}

A dimensão afetiva tem lugar especial na clínica de Ferenczi, tendo ele sido criticado por Freud justamente como tendo sido "o padrinho dos transbordamentos de afeto maternal” (SABOURIN, 1992, p. XII), que, segundo o Pai da Psicanálise, poderiam dirigir jovens analistas a um caminho criticável.

A partir, sobretudo, de 1928, Ferenczi traz à tona os movimentos psíquicos inconscientes do analista como aspectos responsáveis por atravancar ou, na via oposta, impulsionar os resultados terapêuticos a um fim desejável. A atitude do analista, considerada essencial para a mudança oriunda do processo analítico, ganha maior ênfase em Elasticidade da técnica analítica (1928c), texto que sublinha os questionamentos ao modo habitual de proceder do psicanalista.

Aqui, Ferenczi tece críticas a tudo que se coloque de modo apriorístico ao paciente: nestas condições, a relutância do analista em se desfazer de seu saber e a supremacia que muitas vezes a teoria adquire, independentemente da singularidade de cada caso, tornando o paciente algo que se encaixa nessa ou naquela brecha de uma teoria já pronta e nunca passível de erro, pode ser considerado um obstáculo ao descongelamento da análise muito mais proeminente do que supostas resistências do paciente. O autor alerta: a teoria e a atitude do analista precisam ser elásticas, o que, segundo nosso entender, não significa dizer “frouxas”. Mais necessário do que se apegar de maneira aferrada ao próprio saber, é poder agir com tato, que seria “a faculdade de 'sentir com' (Einfühlung): exigência moral de não fazer ao outro aquilo que, em circunstâncias análogas, não gostaríamos que nos fizessem" (1928c/1988, p. 303). A atitude de mestre-escola, dessa forma, não é recomendada para o desenrolar do processo terapêutico, sendo incompatível 
com o tato. Ademais, o psicanalista húngaro distingue tato de "mera intuição ou sentimentalismo", alertando para o fato de que o 'sentir com' deve alternar-se permanentemente com a auto-observação e o julgamento (idem, p. 308). Na busca de desenvolver essa qualidade de tato o analista deve procurar

“...saber quando e como se comunica algo ao analisado, quando se pode declarar que o material fornecido é suficiente para se tirar conclusões; que roupagem dar à comunicação se for o caso; como reagir a uma reação inesperada e desconcertante do paciente; quando se deve calar e esperar outras associações, em que momento o silêncio é uma tortura inútil para o paciente, etc.” (FERENCZI, 1928c/1988, p. 303)

Assim, o que está no cerne das ideias desse texto capital e da noção de tato aí trabalhada é o permanente exame crítico que o analista deve orientar face às suas próprias ações, considerando a possibilidade do erro, da dúvida e da incerteza, ao invés de proceder de modo precipitado. O auto-exame deve ser uma constante do analista para que possa evitar atropelar o paciente com seus dogmas, interpretações e silêncios forçados.

Cabe apontar uma última ressalva trazida por Ferenczi: o tato do analista traduzido em elasticidade da técnica não significa, uma vez mais, a frouxidão, isto é, “ceder sem resistência”, mas sim, a busca do analista de se "colocar no mesmo diapasão do doente, (...) mas nos mantermos firmes (...) em nossa posição ditada pela experiência analítica” (idem, p. 311-2). É possível perceber que adquirir tal “faculdade de sentir com” e proporcionar sua concretização na clínica é caminhar com equilíbrio nos meandros da possibilidade, menos fácil do que pode parecer, de construção do dispositivo psicanalítico.

A relevância concedida ao tato e à elasticidade é retomada por Ferenczi em A criança mal-acolhida e sua pulsão de morte ([1929], 1992), texto no qual discute o problema da pulsão de morte nos momentos iniciais do desenvolvimento da criança e o reflexo de um mal-acolhimento primordial na vida futura do sujeito. Trata-se aqui da ideia a respeito da influência do ambiente inicial nos desenvolvimentos futuros do adulto e do papel da intersubjetividade nesse processo (SOUZA, 2001). Nestes casos, o tato é imprescindível na clínica e o depoimento de Ferenczi mostra ter se encontrado "na obrigação de reduzir (...) as exigências quanto à capacidade de trabalho do paciente" (FERENCZI [1929],1992, p.51). A capacidade de autocrítica constante e a necessidade de prudência no modo de agir do analista foram se tornando mais densos nos últimos artigos produzidos antes do Diário Clínico. Em Análise de crianças com adultos (1931/1988), Ferenczi lança um grande feixe de luz à dificuldade da técnica habitual. A crítica contínua à tendência de intelectualização na análise encontra-se aí na vultosa reprovação à noção de que a associação livre é o caminho inquestionável para o processo terapêutico colocar-se em marcha: 


\begin{abstract}
“Nestes casos aparentemente estagnados em que a análise não traz, já há tempos, nem perspectivas novas nem progressos terapêuticos, tive o sentimento de que o que chamamos associação livre permanece sempre ainda uma seleção muito consciente de pensamentos, e levei então os pacientes a uma 'relaxação' mais profunda, a um abandono mais completo às impressões, tendências e emoções interiores que surgiam espontaneamente." (FERENCZI, 1931/1988, p. 335)
\end{abstract}

Esse texto é conhecido por delinear com mais precisão a aproximação da análise de crianças com a de adultos, que, aliás, já podia ser vislumbrada no texto sobre a criança mal-acolhida (1929): por meio da crítica à ausência de reação do analista, o que motiva a perturbação da associação por parte do paciente, e da exortação à procura de um mergulho mais profundo nas vivências traumáticas passadas, Ferenczi, mais uma vez, procedia a uma inovação do método, valorizando a intensidade do processo. A “análise pelo jogo”, em que o dispositivo analítico se aproxima do jogo de perguntas e respostas que se verifica no atendimento psicanalítico com crianças, torna-se um meio para atingir a investigação analítica com profundidade daquilo que surge como material lúdico atuado ou repetido. O autor húngaro buscava, com isso, que seu trabalho clínico pudesse tocar não apenas as lembranças recalcadas, mas também o que chamou de lembranças subjetivas, como sensações corporais, ou seja, procurava atingir tudo o que se referia à memória de um período arcaico, “o lugar do não-representável, um lugar que não é o do recalcamento, está fora do espaço psíquico da representação pela impossibilidade de rememoração” (FONTES, 2002, p. 41). Dessa forma, voltou sua atenção para o trauma e seu resgate curativo na experiência analítica, o que torna evidente a importância das intensidades no âmbito da prática clínica.

\title{
REPETIÇÃO DO TRAUMA NA ANÁLISE: CONFIANÇA E CONTRASTE
}

Análise de crianças com adultos (1931/1988) é um texto relevante também por trazer à tona a problemática do trauma, resgatada de forma heterodoxa na fase final de sua clínica, e que põe em relevo a dimensão afetiva na cena analítica, além de destacar o papel fundamental da confiança. O autor traça paralelos significativos entre o trauma vivido na infância e o trauma que pode ser repetido na situação de análise, servindo, esse último, para reforçar os sintomas. O modo como Ferenczi recupera a noção de traumatogênese coloca no centro do debate sobre o dispositivo analítico, e sua validade como instrumento terapêutico ou não, a relação entre analista e paciente e, como já se teve oportunidade de sublinhar, a confiabilidade como elemento que suscita o movimento psíquico ou o congela de modo indefinido.

Dessa forma, quando da retomada da importância do traumatismo na gênese dos sintomas e adoecimento dos pacientes, sua preocupação centrou-se tam- 
bém nos elementos do dispositivo analítico que podiam levar à cura e naqueles que suscitavam o movimento contrário. O início de seu Diário Clínico traz apontamentos sobre aquelas que seriam as condições desfavoráveis da análise. Elas remontam à insensibilidade do analista - tema que inaugura o Diário na passagem de 07 de janeiro de 1932 —, à atitude sem afeto por parte do analista e que não favorece o estabelecimento do sentimento de convicção no paciente, caro ao autor para a possibilidade curativa, e ainda a repetição, na análise, do silêncio em relação ao trauma infantil (FERENCZI, 1932/1985, p. 31, 57, 58). Sendo assim, se sua terapêutica ativa anterior contribuía para reativar experiências traumáticas passadas com o objetivo de resolver a compulsão a repetir, Ferenczi observou que isso não acontecia. As ordens e interditos foram deixados de lado até o autor chegar à importância da paciência e da indulgência (BALINT, 1992). O lugar traumatizante da análise é apontado por Ferenczi, que, com isso, traz à baila a possibilidade de um caráter iatrogênico do dispositivo analítico. Se outrora os adultos, em seu silêncio hipócrita face ao sofrimento da criança, contribuíam sem medida para conferir o caráter de trauma a acontecimentos carregados de sofrimento, os analistas não deviam se comportar de igual forma perante a dor de seus pacientes em situação de análise. Em 24 de julho de 1932, Ferenczi tece a seguinte observação em seu Diário clínico:

"O contraste com o ambiente da situação traumática, portanto, a simpatia, a confiança — recíproca — devem ser estabelecidas, antes que se apresente uma nova atitude: a rememoração em vez da repetição. A associação livre, por si só, sem que sejam lançadas novas bases para uma atmosfera de confiança, não proporciona, portanto, uma cura verdadeira. O médico deve se dedicar de corpo e alma ao seu caso ou então, se não o fizer, deverá reconhecê-lo honestamente, ao contrário do comportamento dos adultos com relação às crianças." (FERENCZI, 1932/1985, p. 214)

Em Princípio de relaxamento e neocatarse (1930), Ferenczi trabalha a importância do traumatismo em alguns quadros clínicos nos quais esse fator impera, apontando ainda a dimensão afetiva que se mostra no dispositivo analítico. Nesse texto, o autor preconiza as transgressões ${ }^{1}$ como uma suposta forma correta de proceder do psicanalista com o intuito de alcançar fins terapêuticos. Buscava um comportamento do analista que não se assemelhasse ao daqueles que haviam provocado a situação traumática.

\footnotetext{
${ }^{1}$ As transgressões a que se refere incluem que o paciente não se deite no divã e encare o analista frente a frente, ou que possa deambular dentro do consultório, ou ainda prolongar a sessão analítica até que se esgote a reação emotiva do paciente - procedimento este que pode significar a dedicação de duas ou mais sessões por dia ao paciente (FERENCZI, 1930/1992, p. 58), entre outras.
} 
A liberdade que Ferenczi concedia a si mesmo para permitir-se não seguir à risca as recomendações técnicas que o próprio Freud dedicou a principiantes levou à postulação do princípio do relaxamento ao lado do princípio da frustração em análise. A cristalização da técnica, fixada apenas no princípio da frustração, levava, como observava o autor em sua prática, a um aumento supérfluo da resistência por parte dos pacientes, desaguando em uma repetição do traumático infantil de maneira demasiadamente literal.

Pôde, assim, observar em seus pacientes uma atitude mais flexível que se seguia à relaxação, em oposição a um comportamento fixo, anterior à mudança de método. Sua conclusão foi a de que, pela perspectiva do paciente, pode-se comparar "a reserva severa e fria do analista com a continuação da luta infantil contra a autoridade dos adultos” (1930/1992, p. 61). A mudança proposta na atitude do analista visa uma "economia de sofrimento" que não é a favor de uma anestesia psíquica na vida do analisando, mas que, ao contrário, busca evitar um excesso de sofrimento que ultrapassa aquilo que é necessário.

Contudo, é no texto sobre a Confusão de línguas entre adulto e criança (1933/1992) que se pode encontrar o resgate, de maneira decisiva, da importância do fator traumático no surgimento da neurose e da advertência de que o dispositivo psicanalítico pode repetir o trauma, impossibilitando uma relação de confiança entre paciente e analista. Nesse trabalho, fica patente a estrutura bifásica dos traumatismos infantis patogênicos (BALINT, 1992), em que há dois momentos: o primeiro, em que o bebê ou a criança é submetida a uma hiper ou hipoestimulação oriunda de adultos importantes em sua vida; e a segunda fase, que tem um papel crucial na formação do trauma, na qual a criança busca uma reparação ou compreensão por parte de tais adultos, obtendo em troca apenas a negação do que ocorreu na primeira fase, o que acaba por impedir o percurso do processo de introjeção (PINHEIRO, 1995, p.73).

Trata-se aí do desmentido do adulto, que Ferenczi discute em artigos publicados depois de sua morte, nos quais assinala que o comportamento do adulto face à criança que passou pelo traumatismo é parte do "modo de ação psíquica do trauma” (FERENCZI, 1931b/1992, p. 110). Assim, para que o trauma se estabeleça, é necessário o momento posterior de quebra da confiança, quando o adulto desmente o sofrimento vivido pela criança e, a partir daí, é o silêncio, ou até mesmo a punição, aquilo que resta da vivência traumática.

Desse modo, Ferenczi assevera que a análise deveria ser aprofundada de modo a permitir, por intermédio da ab-reação, que "quantidades importantes de afetos recalcados se impusessem à vida afetiva consciente e pudessem em breve pôr fim ao surgimento de sintomas (...)” (1933/1992, p. 97-8). No entanto, essa revivescência como sendo o objetivo a ser perseguido na experiência analítica, há que trazer uma resolução diferente daquela vivida na infância, qual seja, o analista 
não deve, como o adulto do passado, desmentir o sofrimento ou repeti-lo por intermédio de uma atitude similar à daqueles que impuseram o trauma.

É possível notar que o resgate do trauma no plano das ideias e a importância da neocatarse a ele atrelada colocam em destaque o papel dos fatores afetivos no processo terapêutico, vinculados intimamente à confiança no analista. Ferenczi, revisitando, nesse texto, a história da psicanálise e as modificações empreendidas no que se refere à técnica, afirma ter ela se tornado um "processo essencialmente intelectual” por converter-se numa "espécie de experiência infinita de associações” (FERENCZI, 1933/1992, p. 55). A importância que ele atribui à afetividade pode ser aqui encontrada, quando demonstra que, por fim, fracassos terapêuticos de Freud o teriam levado a

"restabelecer a afetividade na relação analista-analisando, que tinha sido manifesta e erroneamente negligenciada durante um certo tempo. (...) [Isso era feito] conferindo mais atenção e valor aos sinais de transferência de afetos e de resistência afetiva que se manifestavam na relação analítica." (FERENCZI, 1933/1992, p. 55)

Dessa maneira, o texto publicado em 1933 e as conclusões que desenvolve nos escritos íntimos do Diário constituem um momento importante da obra do autor húngaro, o arremate final que permitiu costurar temas que já vinham sendo tratados com especial atenção desde 1928: tem-se aí o desenho mais preciso da ênfase dada à dimensão afetiva da relação analítica, da função da confiabilidade e da crítica severa à intelectualização no tratamento psicanalítico. A insinceridade do analista e o repúdio de sentimentos contratransferenciais são amplamente problematizados nesse artigo.

Acredita-se, aqui, que a originalidade de Ferenczi ao retomar o traumatismo na gênese das neuroses consiste no paralelo que pode assumir com o tratamento psicanalítico quando o mesmo contém em si as tais condições desfavoráveis, enumeradas nas páginas de seu Diário clínico. O autor não nega a possibilidade de existir, de modo dissimulado e mascarado, no analista, uma antipatia face ao paciente e, muitas vezes, impulsos sádicos. ${ }^{2}$ Nos dizeres do psicanalista húngaro, é de fato a confiança do paciente "aquele algo que estabelece o contraste entre o presente e o passado insuportável e traumatogênico” (1933/1992, p. 100). A confiabilidade parece ser, por conseguinte, o cerne da questão, tanto no que se refere ao trauma, quanto àquilo que remete ao desenrolar terapêutico e depende do trânsito de afetividade no âmbito da relação analítica, como se pode depreender do trecho seguinte:

\footnotetext{
${ }^{2}$ Em 13 de agosto de 1932, Ferenczi refere-se explicitamente ao prazer sádico que pode estar presente no analista (Diário clínico).
} 
“É como se duas metades da alma se completassem para formar uma unidade. Os sentimentos do analista entrelaçam-se com as ideias do analisado e as ideias do analista (imagens de representações) com os sentimentos do analisado. Desse modo, as imagens que de outro modo permaneceriam sem vida tornam-se episódios, e as tempestades emocionais, sem conteúdo, enchem-se de um conteúdo representativo." (FERENCZI, trecho de 19 de janeiro de 1932/1985, p.45)

Porém, é importante salientar que muitas vezes a confiabilidade só é possível ser alcançada após a vivência de "anomalias da crença — credulidade ilimitada, dúvida patológica ou ceticismo e desconfiança sistemáticas”, considerados por Ferenczi como sendo sintomas regressivos presentes no cotidiano da prática clínica (FERENCZI, 1913/1992, p.29).

Não se pode deixar aqui de referir, como é amplamente sabido, o fato de que o tema da confiabilidade é retomado por Winnicott, quando traz elaborações relevantes acerca da confiança no ambiente e da confiança no analista, elementos chave para a espontaneidade e a criatividade, tanto na vida, quanto no processo psicoterápico. Para o desenvolvimento do brincar da criança, que é, segundo esse autor, localizado no espaço potencial entre a mãe e o bebê, é necessário que haja o estado de confiança na fidedignidade da mãe ou da figura materna. De igual modo, para que se possa realizar a psicoterapia, essa confiança também se faz necessária. É preciso de um estado tal em que o paciente possa atingir condições para o relaxamento, propiciado pelo ambiente terapêutico, proposição esta que converge com o relaxamento preconizado por Ferenczi como elemento que leva à diminuição da resistência do paciente. Assim, ele poderá exercer sua criatividade no processo de cura (WINNICOTT, 1975). Dessa forma, a prática clínica tanto de Ferenczi quanto de Winnicott (e também de M. Balint) é calcada na confiança e na afetividade, elementos para os quais o autor húngaro já pedia a devida atenção. Ainda assim, muitas vezes se esquece de mencioná-lo como um dos primeiros autores a dirigir enfaticamente sua preocupação a tais aspectos primordiais da experiência psicanalítica.

\section{ANÁLISE MÚTUA: DESDOBRAMENTOS FINAIS}

Após percorrermos parte do trajeto de Ferenczi e do desenvolvimento de suas ideias no último período de sua vida, não é sem importância dedicar uma atenção a essa que foi a derradeira inventiva metodológica de sua carreira como psicanalista. A análise mútua, tratada com afinco nas páginas de seu Diário clínico, desperta o interesse menos por sua ousadia clínica, que não deixa de surpreender, do que pelos questionamentos que suscita sobre numerosos fatores do comportamento, da intervenção e dos sentimentos do analista no desenrolar dos processos psicoterápicos que conduz. A análise mútua é o resultado da in- 
tensificação da importância que Ferenczi atribuía à sinceridade do analista no decurso da experiência psicanalítica. Acredita-se aqui que a leitura de seu relato é enriquecedora por permitir o confronto com reflexões que devem constituir o cotidiano do analista, seja ele realizado em consultório, seja, parafraseando-o, nas instituições “difíceis”.

As anotações de 5 de maio de 1932 trazem o relato sobre o início desse empreendimento clínico. A análise mútua teria começado, neste sentido, com a paciente R.N., pela qual Ferenczi nutria uma rejeição que tentou compensar através de uma exagerada e artificial simpatia. Tal paciente, pressupondo sentimentos de ódio em Ferenczi, exigiu que o pudesse analisar, sendo que após um ano de resistência por parte dele, iniciaram a análise mútua, que foi se tornando sistemática, com sessões alternadas ou duplas, sendo uma hora para ela e outra para ele (DUPONT, 1985). De acordo com seu relato, Ferenczi teria obtido desse empreendimento inédito alguns bons efeitos: para sua surpresa a paciente tinha razão e seus complexos maternos foram sendo desvendados analiticamente e mostrando sua relação com os sentimentos contratransferenciais que nutria pela paciente-analista e, finalmente, as benesses da técnica foram estendidas também a outros pacientes.

Não é difícil supor que Ferenczi chegou também a questões acerca dos limites da análise mútua, como se lê na passagem de 3 de março de 1932: "Cada vez mais me pareceu indigno agir como se tivesse me virado muito bem com a mutualidade, quando na verdade só realizei a minha 'autoanálise' com uma considerável reservatio mentalis” (1932/1985, p. 80). Pode-se ter um julgamento crítico negativo da técnica da mutualidade, uma vez que já se tem o parâmetro de algo anterior: as regras arroladas por Freud e que, de início, também poderiam ser muito arbitrárias, mesmo com todas as justificativas teóricas impregnadas de racionalidade para fundamentá-las, e mesmo considerando que seriam regras que convinham a seu temperamento, podendo não ser por todos adotadas (BIRMAN, 1988).

Não é impossível aventar a hipótese de que se o padrão criado por Freud para o estabelecimento da psicanálise fosse o da análise mútua, talvez a ela os psicanalistas estivessem habituados, exprobrando a ruptura de Ferenczi com tais normas, caso propusesse a abstinência e maior neutralidade. Vale dizer, a variabilidade é uma característica da técnica psicanalítica e, em termos da própria perspectiva de Freud, não é possível concebê-la como algo normatizado e universal (BIRMAN, 1988). Apesar disso, não se quer, com os argumentos aqui apresentados, defender sua adoção; o que se deseja é, antes, salientar a liberdade de criação que Ferenczi permitia a si mesmo no trato com os pacientes, sempre visando fins terapêuticos e, na maioria das vezes, chegando à autocrítica necessária para continuar com eles ou perceber suas contraindicações. 
Não obstante as problemáticas do cotidiano clínico que a análise mútua de Ferenczi levanta, sabe-se, ainda assim, que elas não podem ser tão facilmente solucionadas, o que não significa que se as deva ignorar. A análise mútua é uma busca desesperada pelo contraste entre a situação analítica e o passado doloroso da infância, através de um recrudescimento da sinceridade com o paciente. No entanto, Ferenczi não deixava de apontar que seria necessário estar avançado na análise e avaliar a sensibilidade do paciente, isto é, o que ele poderia aguentar e sustentar daquilo que ouviria do analista.

A preocupação com o trauma e com a clivagem da personalidade perpassa as anotações do Diário e rondam a mutualidade: Ferenczi procurava a reunificação da personalidade de seus pacientes e identificava o sentimento de convicção como o elemento que permitiria, se duradouro, a reintegração tão desejada. Neste sentido, os passos que levariam à convicção do paciente quanto ao vivido traumático, após a repetição do trauma na situação analítica, estavam atrelados aos afetos do analista, à sua capacidade de se deixar tocar pelo sofrimento do paciente, à sua habilidade de reagir de modo emocional, ao invés de uma atitude reservada, fria ou mesmo presunçosa. Quando o analista de fato é afetado por aquilo que diz respeito a seu paciente, "sentindo com" o analisando, a convicção e o contraste com o passado traumático podem assim se estabelecer. Em resumo, para Ferenczi, a recuperação que leva à cura é inextricavelmente ligada à relação entre analista e analisando: relação que, se imbuída de amor e sinceridade, serve como contrapeso ao trauma. Ainda assim, esse autor não deixava de reconhecer as fraquezas que podem fazer parte da constituição do analista: não se pode esperar que a compaixão e a abnegação estejam sempre presentes, mas reconhecer sua ausência ou mesmo a presença de seus opostos seria a pedra de toque para que o dispositivo analítico pudesse trazer benefícios e o alívio de uma dor antiga.

É importante frisar que, apesar da importância da contribuição ferencziana para as reflexões a respeito da prática clínica, não se pode deixar de observar que talvez não seja possível dizer tudo ao paciente, dando curso à associação livre, como Ferenczi a princípio pretendeu e, depois, colocou em questão. Talvez não seja sempre possível deixar de atender o paciente quando o analista se encontra cansado ou irritado, ou quiçá seja um tema fundamental a ser discutido este que é o das implicações dos sentimentos contratransferenciais ou as condições de cansaço, impaciência e tédio que podem surgir no dia a dia do trabalho. Fato é que, independente de como isso se traduzirá na intervenção clínica e como todos esses aspectos se relacionam com o aparato teórico construído na psicanálise, estes são temas que não podem estar do lado de fora do refletir do analista sobre seu trabalho. Ferenczi trouxe à superfície pontos que fazem parte da tessitura do campo 
analítico e têm, quer se queira ou não, ou ainda, quer se possa perceber ou não, efeitos não desprezíveis na construção da experiência psicanalítica.

Recebido em 21/11/2007. Aprovado em 25/8/2008.

\section{REFERÊNCIAS}

BALINT, M. (1968/1993). A falha básica: aspectos terapêuticos da regressão. Porto Alegre: Artes Médicas.

BIRMAN, J. (1988) "Confusão de língua na psicanálise. Uma leitura introdutória aos escritos de Ferenczi”, in BIRMAN, J. (Org.) S. Ferenczi, escritos psicanalíticos 1909-1933. Rio de Janeiro: Taurus.

BORGES, H. (2002) “A arte dos começos”, in PlAStinO, C. A. (Org.) Transgressões. Rio de Janeiro: Contracapa Livraria.

DUPONT, J. (1985) “Prefácio”, in FERENCZI, S. Diário clínico. São Paulo: Martins Fontes.

FERENCZI, S. (1933/1985) Diário clínico. São Paulo: Martins Fontes. (1909/1988) “Transferência e introjeção”, in BIRMAN, J. (Org.) S. Ferenczi, escritos psicanalíticos 1909-1933. Rio de Janeiro: Taurus. (1913/1992) "Fé, incredulidade e convicção sob o ângulo da psicologia médica”, in Psicanálise II. São Paulo: Martins Fontes. (1928a/1992) "A adaptação da família à criança”, in Psicanálise IV. São Paulo: Martins Fontes. (1928c/1988) "Elasticidade da técnica analítica", in BIRMAN, J. (Org.) S. Ferenczi, escritos psicanalíticos 1909-1933. Rio de Janeiro: Taurus.

(1929/1992) "A criança mal-acolhida e sua pulsão de morte". In Psicanálise IV. São Paulo: Martins Fontes.

(1930/1992) "Princípio de relaxamento e neocatarse (1930)", in Psicanálise IV. São Paulo: Martins Fontes.

(1931/1988) "Análise de crianças com adultos", in BIRMAN, J. (Org.) S. Ferenczi, escritos psicanalíticos 1909-1933. Rio de Janeiro: Taurus.

(1931b/1992) "Artigos póstumos. Reflexões sobre o trauma”, in Psicanálise IV. São Paulo: Martins Fontes.

(1932/1992) “Notas e fragmentos”, in Psicanálise IV. São Paulo: Martins Fontes.

(1933/1992) "Confusão de língua entre os adultos e a criança", in Psicanálise IV. São Paulo: Martins Fontes.

FONTES, I. (2002) Memória corporal e transferência: fundamentos para uma psicanálise do sensível. São Paulo: Via Lettera Editora e Livraria.

LAGACHE, D. (1980) La teoria de la transferencia, Buenos Aires: Nueva Vision. 
PEIXOTO JUNIOR, C. A. (2004) A atualidade teórica e clínica do pensamento de Michael Balint: uma contribuição para a abordagem do paciente borderline. Alter - Jornal de Estudos Psicanalíticos, v. 22, n. 2, Brasília, p. 215-230.

PINHEIRO, M. T. (1994) “Trauma e melancolia”, in KATZ, C. Férenczi: história, teoria, técnica. Rio de Janeiro: Editora 34. UFRJ.

REIS, E. S. (2004) De corpos e afetos: transferências e clínica psicanalítica. Rio de Janeiro: Contra Capa Livraria.

SABOURIN, P. (1992) "Prefácio: Vizir secreto e cabeça de turco", in FERENCZI, S. Psicanálise IV. São Paulo: Martins Fontes.

SABOURIN, P. (1985) "Posfácio: Perdão mútuo, sucesso final!", in FERENCZI, S. Diário clínico. São Paulo: Martins Fontes.

SOUZA, Octavio. (2001) "Nota sobre algumas diferenças na valorização dos afetos nas teorias psicanalíticas”, in BEZERRA JR, B., PLASTINO, C. A. (Orgs.) Corpo, afeto, linguagem: a questão do sentido hoje. Rio de Janeiro: Marca D'água.

VERZTMAN, J. S. (2002) O observador do mundo: a noção de clivagem em Ferenczi. Ágora, Rio de Janeiro, v.5, n.1. Disponível em: <http://www.scielo.br/scielo.php?script=sci_arttext\&pid=S151614982002000100005\&lng=pt\&nrm=iso >. Acesso em: 19 de julho 2007. Pré-publicação.

WINNICOTT, D. (1975) O brincar e a realidade. Rio de Janeiro: Imago.

Vivian Heringer Pizzinga

vivianhp@globo.com

Márcia Arán

marciaaran@terra.com.br 